Article

\title{
Floral Resources for Trissolcus japonicus, a Parasitoid of Halyomorpha halys
}

\author{
Hanna R. McIntosh $1,2, * \mathbb{C}$, Victoria P. Skillman ${ }^{3}$, Gracie Galindo ${ }^{2}$ and Jana C. Lee ${ }^{2}$ \\ 1 Department of Entomology, University of Wisconsin-Madison, Madison, WI 53706, USA \\ 2 Horticulture Crops Research Unit, USDA-ARS, Corvallis, OR 97331, USA; \\ gracie.galindo@usda.gov (G.G.); jana.lee@usda.gov (J.C.L.) \\ 3 Hermiston Agricultural Research and Extension Center, Oregon State University, Hermiston, OR 97838, USA; \\ skillmav@oregonstate.edu \\ * Correspondence: hrmcintosh@wisc.edu
}

Received: 2 June 2020; Accepted: 26 June 2020; Published: 3 July 2020

check for

\begin{abstract}
The egg parasitoid Trissolcus japonicus is the main candidate for classical biocontrol of the invasive agricultural pest Halyomorpha halys. The efficacy of classical biocontrol depends on the parasitoid's survival and conservation in the agroecosystem. Most parasitoid species rely on floral nectar as a food source, thus identifying nectar sources for T. japonicus is critical. We evaluated the impact of eight flowering plant species on T. japonicus survival in the lab by exposing unfed wasps to flowers inside vials. We also measured the wasps' nutrient levels to confirm feeding and energy storage using anthrone and vanillin assays adapted for T. japonicus. Buckwheat, cilantro, and dill provided the best nectar sources for T. japonicus by improving median survival by $15,3.5$, and 17.5 days compared to water. These three nectar sources increased wasps' sugar levels, and cilantro and dill also increased glycogen levels. Sweet alyssum, marigold, crimson clover, yellow mustard, and phacelia did not improve wasp survival or nutrient reserves. Further research is needed to determine if these flowers maintain their benefits in the field and whether they will increase the parasitism rate of $H$. halys.
\end{abstract}

Keywords: biological control; biocontrol; brown marmorated stink bug; conservation; flowers; survival; longevity; nectar subsidy; samurai wasp

\section{Introduction}

The brown marmorated stink bug, Halyomorpha halys (Stål), is a polyphagous agricultural pest that has spread from its native range in Asia to the United States [1], Canada [2], Europe [3], and Chile [4] in the last 25 years. Halyomorpha halys feeds on cultivated fruits, vegetables, row crops, ornamentals, and wild host plants [5]. Due to its wide host range, dispersal capacity, and voracious feeding by nymphs and adults, $H$. halys causes substantial economic damage $[5,6]$. Infestations are largely controlled by insecticides, which is costly to growers, has limited efficacy, is not compatible with integrated pest management strategies [7], and risks insecticide resistance and secondary pest outbreaks. Management is especially difficult in organic production since fewer effective insecticides are approved [8]. Thus, recent research aims to develop alternative management practices, including classical biological control.

The samurai wasp, Trissolcus japonicus (Ashmead), is the main candidate for classical biocontrol of H. halys. This egg parasitoid can kill up to $70 \%$ of $H$. halys eggs in the insects' native range [9]. Trissolcus japonicus has been studied in quarantine as a potential biocontrol agent for $H$. halys since 2017 [6], but adventive populations genetically distinct from those in quarantine were found in Maryland [10] and Washington State [11] in 2014 and 2015. Since then, T. japonicus has been detected in Virginia, West Virginia, Delaware, New Jersey, New York, the District of Columbia [5], Oregon [12], Ohio, 
Pennsylvania [5], and Michigan [13]. While T. japonicus continues to spread to new areas in the United States, its parasitism rate remains low. In New Jersey, the parasitism rate was $2.2 \%$ in peach and $0 \%$ in apple [14]. More research is needed to improve biocontrol, including strategies for rearing, release, augmentation, and conservation. The efficacy of T. japonicus as a biocontrol agent depends on its survival and conservation in the agroecosystem.

Identifying nectar sources for T. japonicus is critical since most parasitoid species feed on floral nectar [15]. Floral nectar sources have also shown to improve parasitoid longevity or fecundity in the field [16,17], thus biocontrol may be improved by nectar subsidies [18]. However, simplified agroecosystems may not provide the right plant species or may lack temporal continuity of flowering plants. Further, not all flowers are sufficient nectar sources for parasitoids. Flowers with long or complex corollas inhibit foraging by small wasps with short mouthparts [19-22]. Furthermore, not all nectar has optimal nutritional characteristics for parasitoids, which usually depend on specific amino acid compositions and sucrose to hexose ratios [23]. Thus, there is a need to identify plants that provide suitable nectar sources for the T. japonicus to help improve survival and conservation in the agroecosystem.

This study tested eight flowering plants as potential nectar sources for T. japonicus: sweet alyssum (Lobularia maritima (L.) Desv.), marigold (Tagetes patula L.), buckwheat (Fagopyrum esculentum Moench), cilantro (Coriandrum sativum L.), crimson clover (Trifolium incarnatum L.), dill (Anethum graveolens L.), yellow mustard (Guillenia flavescens (Hook.) Greene), and phacelia (Phacelia tanacetifolia Benth.). We evaluated the impact of each of these eight plants on T. japonicus survival in the lab. Honey water was used as a positive control, since T. japonicus can live over $40 \mathrm{~d}$ on honey water in the laboratory [24]. A review of floral resources for parasitoids found that many of these plants or closely-related species are attractive to parasitoids and improve longevity [15]. Further, buckwheat, marigold, cilantro, and phacelia were shown to improve longevity of Trissolcus basalis, another important parasitoid of stinkbugs [25]. We were also interested in marigold due to its allelopathic suppression of parasitic nematodes [26] and ability to improve the parasitism rate of Aphidius platensis Brethes [27]. To confirm that wasps fed on flowers and gained energy reserves, lipid, glycogen, and sugar levels were measured in wasps following feeding [28].

\section{Materials and Methods}

\subsection{Insect Colonies}

All colonies were maintained at the USDA ARS Horticultural Crops Research Unit in Corvallis, OR. The $H$. halys colony was started and maintained from wild-collected bugs. Adults and nymphs were collected via beat sheet from May to November at multiple sites across the Willamette Valley, mostly from cultivated holly plants (Ilex aquifolium). When wild bugs were in winter diapause, adults were collected from aggregations in local residences. The colony was replenished with new adults throughout the year, so that all individuals were wild-collected and none were reared from eggs laid in the lab colony. Bugs were contained in $29.5 \times 29.5 \times 30.5 \mathrm{~cm}$ plastic mesh cages (Bug Dorm, BioQuip, Rancho Dominguez, CA, USA) inside a growth chamber $\left(21-22{ }^{\circ} \mathrm{C}, 16: 8 \mathrm{~L}: \mathrm{D}, 60-70 \% \mathrm{RH}\right)$. Each cage included 20-80 adults. Each cage contained carrots, raw unsalted peanuts and/or sunflower seeds, jellybeans, and a water wick.

The T. japonicus colony was established in 2017 from field populations in Portland, Oregon, collected from sentinel and wild egg masses. Wasps were contained in $\sim 473 \mathrm{~mL}$ plastic-lined paper soup cups with plastic lids (Huhtamaki Inc., Espoo, Finland). Four colony cups were stored inside $29.5 \times 29.5 \times 30.5 \mathrm{~cm}$ Bug Dorm cages in the lab $\left(\sim 21^{\circ} \mathrm{C}\right.$, natural day length conditions, $\left.\sim 60 \% \mathrm{RH}\right)$. A small section of filter paper soaked in $50 \%$ honey/water solution was provided each weekday, along with 4-8 H. halys egg masses per week. We used fresh egg masses when available and supplemented with frozen egg masses when necessary [29]. 


\subsection{Survival/Longevity}

We tested the impact of 8 flowers on T. japonicus survival in a series of trials in the lab (Table 1), which were conducted based on flower availability. Treatments in trial 1 included sweet alyssum, Nema-gone marigold (Burpee, Warminster, PA, USA), honey (positive control), and water (negative control). Treatments in trial 2 included buckwheat, honey, and water. Treatments in trial 3 included cilantro, crimson clover, dill, mustard, phacelia, honey, and water. All flowers were grown from seed in the Professional Growing Mix (Sun Gro ${ }^{\circledR}$ Horticulture, Agawam, MA, USA) in a greenhouse at the USDA ARS Horticulture Research Unit in Corvallis, OR, USA.

Table 1. Summary of trials. Newly emerged, unfed wasps were placed in vials with each treatment and evaluated for $30 \mathrm{~d}$ (trials 1 and 2) or until all wasps were dead (trial 3). For nutrient trials, wasps were fed for $48 \mathrm{~h}$ and nutrients were measured using anthrone and vanillin assays adapted for Trissolcus japonicus.

\begin{tabular}{|c|c|c|c|c|}
\hline Trial & Measurement & Sex & $\begin{array}{c}\text { Treatment (Number of Wasps, Number of } \\
\text { Vials) }\end{array}$ & Dates \\
\hline \multirow{2}{*}{1} & \multirow{2}{*}{ survival (30 d) } & $\mathrm{f}$ & $\begin{array}{c}\text { alyssum }(51,15), \text { marigold }(58,16) \text {, honey }(47,13) \text {, } \\
\text { water }(50,14)\end{array}$ & \multirow{2}{*}{ May-August 2017} \\
\hline & & $\mathrm{m}$ & $\begin{array}{c}\text { alyssum }(41,15), \text { marigold }(41,16), \text { honey }(29,13), \\
\text { water }(36,14)\end{array}$ & \\
\hline \multirow{2}{*}{2} & \multirow{2}{*}{ survival (30 d) } & $\mathrm{f}$ & buckwheat $(49,13)$, honey $(15,3)$, water $(16,3)$ & \multirow{2}{*}{$\begin{array}{c}\text { September } \\
\text { 2017-March } 2018\end{array}$} \\
\hline & & $\mathrm{m}$ & buckwheat $(29,13)$, honey $(8,3)$, water $(14,3)$ & \\
\hline \multirow[b]{2}{*}{3} & \multirow{2}{*}{$\begin{array}{l}\text { survival } \\
\text { (until dead) }\end{array}$} & $\mathrm{f}$ & $\begin{array}{c}\text { cilantro }(35,5), \text { crimson clover }(35,5), \text { dill }(35,5), \\
\text { mustard }(36,7), \text { phacelia }(35,5), \text { honey }(35,5), \\
\text { water }(99,15)\end{array}$ & \multirow{2}{*}{$\begin{array}{l}\text { June-September } \\
2019\end{array}$} \\
\hline & & $\mathrm{m}$ & $\begin{array}{c}\text { cilantro }(5,5) \text {, crimson clover }(5,5) \text {, dill }(5,5), \\
\text { mustard }(11,7), \text { phacelia }(5,5) \text {, honey }(15,5), \\
\text { water }(15,15)\end{array}$ & \\
\hline 4 & $\begin{array}{l}\text { nutrient levels } \\
\quad(2 \mathrm{~d})\end{array}$ & $\mathrm{f}$ & $\begin{array}{c}\text { alyssum }(30,9) \text {, marigold }(30,7) \text {, buckwheat }(30, \\
7) \text {, honey }(30,9) \text {, water }(30,9)\end{array}$ & 6-26 June 2018 \\
\hline 5 & $\begin{array}{l}\text { nutrient levels } \\
\quad(2 \mathrm{~d})\end{array}$ & $\mathrm{f}$ & $\begin{array}{l}\text { cilantro }(30,4), \text { crimson clover }(30,4) \text {, dill }(30,4), \\
\text { mustard }(30,5), \text { phacelia }(30,4), \text { water }(50,9)\end{array}$ & June-July 2019 \\
\hline
\end{tabular}

Treatment vials were set up on three or more dates with emerging wasps divided between treatments (see Table 1 for vial and wasp numbers and dates). Treatments were set up in $9 \times 3 \mathrm{~cm}$ (diameter) plastic vials with cotton plugs and $2 \mathrm{~mL}$ microcentrifuge tube 'vases' glued inside. Vases were filled with water, and flowers were inserted wrapped in cotton to prevent wasps from drowning. Each vase contained one stem of a single flower treatment. Water control vials included only an empty vase of water plugged with cotton. Honey control vials did not contain a vase and had a small piece of filter paper dipped into a 50:50 honey:water solution stuck to the inside of the vial.

After flower set-up, 3-8 newly emerged ( $<1 \mathrm{~d}$ old), unfed $T$. japonicus were introduced into each vial. All vials included adult females and males, but the number of each sex varied by availability in the colony. To promote normal oviposition behavior, all vials contained one H. halys egg mass $(<3 \cdot \mathrm{d}$ old at harvest, stored at $-80^{\circ} \mathrm{C}$ ) affixed to the cotton plug with double-sided tape; egg masses were changed weekly. Flowers were changed and vases were refilled every Monday, Wednesday, and Friday. Honey was changed every weekday.

After assembly, wasps were monitored every weekday for mortality. Wasps that were missing, stuck in honey or water, or had escaped during flower changing were marked as such and censored in the data set. To account for unknown day of death on weekends, wasps recorded as dead on Mondays were marked and 1.5 was subtracted from their day of death. Trials 1 and 2 were ended after 30 days or 
earlier if all wasps died. Wasps surviving to 30 days were marked as censored. For trial 3, we wanted to assess longevity more comprehensively, thus trials ended after all wasps died.

\subsection{Nutrient Levels}

Wasps exposed to the 8 flower treatments were measured for nutrient levels to confirm feeding and energy storage. Only female wasps were tested since their feeding would extend their oviposition period. Trial 4 combined treatments from survival trials 1 and 2 (sweet alyssum, marigold, buckwheat, honey, water). Trial 5 used the same treatments as longevity trial 3 (cilantro, crimson clover, dill, mustard, phacelia, honey, water). Vials were set up as described for the survival studies with newly emerged wasps, except flowers were not changed and egg masses were not provided. Wasps were removed from vials after $48 \mathrm{~h}$ and frozen at $-80^{\circ} \mathrm{C}$.

Lipid, glycogen, and total sugar levels were measured following anthrone and vanillin assays [30,31] adapted for T. japonicus [28]. Protocols were adjusted to have $250 \mu \mathrm{L}$ reaction volumes due to the small size of T. japonicus. Individual wasps were crushed in $13 \mu \mathrm{L}$ sodium sulfate in a $1.5 \mathrm{~mL}$ microcentrifuge tube with a pestle. Next, $113 \mu \mathrm{L}$ of chloroform:methanol (1:2) was added, vortexed, and centrifuged for $2 \mathrm{~min}$ at 13,000 rpm. The supernatant was poured into a glass tube, and the glycogen precipitate was reacted with $240 \mu \mathrm{L}$ of anthrone reagent by vortexing and heating at $90{ }^{\circ} \mathrm{C}$ for $3 \mathrm{~min}$. After cooling on ice, the glycogen samples were pipetted into 96-well plates (Costar 3590, Corning Inc., Corning, NY, USA) and read at $630 \mathrm{~nm}$ on a spetrophotometer (BioTek ELX, BioTek Instruments, Winooski, VT, USA). The supernatant was divided in half into two glass tubes. One tube was evaporated at $90{ }^{\circ} \mathrm{C}$ for $1-2 \mathrm{~min}$ until $10 \mu \mathrm{L}$ of solution remained and was reacted with $240 \mu \mathrm{L}$ anthrone at $90^{\circ} \mathrm{C}$ for $3 \mathrm{~min}$. Cooled sugar samples were read on a spectrophotometer at $630 \mathrm{~nm}$. The other supernatant tube was evaporated at $90{ }^{\circ} \mathrm{C}$ for 3-4 min until nearly dry. Then, $10 \mu \mathrm{L}$ of sulfuric acid was added and heated at $90{ }^{\circ} \mathrm{C}$ for $30 \mathrm{~s}$. Once cooled, $240 \mu \mathrm{L}$ of vanillin reagent was added and reacted for $20 \mathrm{~min}$ at room temperature. Lipid samples were read on a spectrophotometer at $490 \mathrm{~nm}$.

Standard calibrations were made for each reagent to later convert absorbance readings from wasps. The lipid calibration included three replicates of $1,5,10,15$, and $20 \mu \mathrm{g}(=1 \mu \mathrm{L})$ of lipid (50 mg canola oil in $50 \mathrm{~mL}$ chloroform) and control. The same procedures were followed to evaporate the solution, heated with sulfuric acid, reacted with vanillin in a $250 \mu \mathrm{L}$ reaction volume, and read on a spectrophotometer. The sugar (50 mg sucrose in $50 \mathrm{~mL}$ of $25 \%$ ethanol) and glycogen (50 mg beef liver (Fisher Scientific, Waltham, MA, USA) in $50 \mathrm{~mL}$ purified water) calibration included three replicates of $1,5,10,15$, and $20 \mu \mathrm{g}$ and control. The $20 \mu \mathrm{g}(\mu \mathrm{L})$ sample was briefly heated at $90^{\circ} \mathrm{C}$ to bring the volume down. Anthrone reagent was added for a final volume of $250 \mu \mathrm{L}$, heated at $90{ }^{\circ} \mathrm{C}$ for $5 \mathrm{~min}$, and read on a spectrophotometer.

\subsection{Data Analysis}

For survival studies, Kaplan-Meier survival curves were generated and tested by log-rank analyses using PROC LIFETEST [32]. Data were analyzed separately for each trial and each sex. Combining both sexes may skew results since there were variable ratios of sexes per treatment and we observed females to live longer than males. Post-hoc tests compared each pair by log-rank analysis with an adjusted Sidak $p$-value.

To convert absorbance readings from wasps to nutrient values, the relationships between nutrient mass ( $\mu g, x$-axis) and absorbance ( $y$-axis) from standard calibrations were fitted to linear models with the intercept at 0 using JMP 15.0. For lipids, the slope calculated was $0.0327\left(p<0.0001, \mathrm{r}^{2}=0.901\right)$ and $0.0233\left(p<0.0001, \mathrm{r}^{2}=0.948\right)$ in 2018 and 2019, respectively. For glycogen, the slope was 0.051 $\left(p<0.0001, \mathrm{r}^{2}=0.741\right)$ and $0.107\left(<0.0001, \mathrm{r}^{2}=0.823\right)$ in 2018 and 2019, respectively. For sugars, the slope was $0.194\left(p<0.0001, \mathrm{r}^{2}=0.951\right)$ and $0.191\left(p<0.0001, \mathrm{r}^{2}=0.951\right)$ in 2018 and 2019, respectively. Absorbance readings from each wasp were divided by the slope from the calibration line to estimate nutrient content. Since the supernatant was divided in half, sugar and lipid readings were multiplied by two. Nutrient levels of wasps were analyzed by generalized linear mixed models with treatment 
as a fixed effect and vial as a random effect using a lognormal distribution in PROC GLIMMIX [32]. Dunnett tests were used to compare treatments to the water control. Separate analyses were done by nutrient (lipid, glycogen, or sugar), sex, and trial. Tukey post-hoc tests were used for multiple pairwise comparisons.

\section{Results}

All raw data is included in Table S1.

\subsection{Survival/Longevity}

Results for females are presented here. Results for males are given in the Appendix A, since the results are similar but had low replication due to the 80:20 female:male sex ratio of the colony (Table A1, Figure A1). Moreover, the longevity of males is less critical since males patrol egg masses waiting to mate with emerging females.

In trial 1, treatment impacted female T. japonicus survival $\left(\chi^{2}=110.98, \mathrm{df}=3, p<0.0001\right.$; Figure 1$)$. Wasps fed with honey survived significantly longer than wasps fed with water, as expected. Wasps fed with alyssum or marigold did not survive longer than the water control. The median survival for females, when $50 \%$ of wasps were alive, was 4.5 days when fed with water, 6 days when fed with marigold or alyssum, and 28 days when fed with honey.

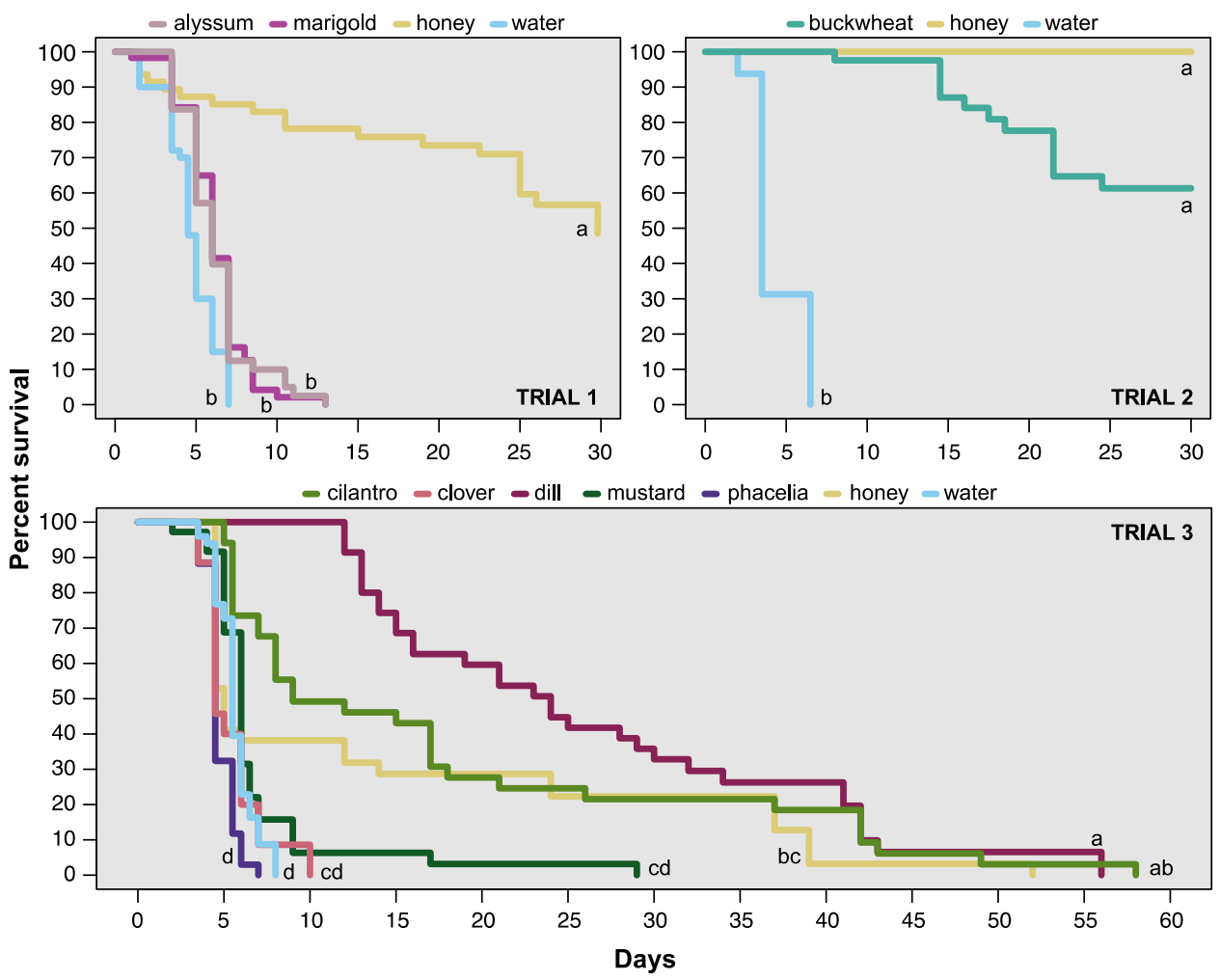

Figure 1. Survival curves of female Trissolcus japonicus fed with flower treatments, honey, or water inside vials in the lab. Per results of log-rank analysis and post-hoc tests, lines with different letters are significantly different from each other.

In trial 2, the treatment impacted female T. japonicus survival $\left(\chi^{2}=101.99, \mathrm{df}=2, p<0.0001\right.$; Figure 1), and wasps fed with buckwheat survived significantly longer than wasps fed only with water. Survival on buckwheat was equivalent to survival on honey. The median survival for females was 3.5 days when fed with water, and more than $50 \%$ of wasps were still alive at 30 days when fed with buckwheat or honey. 
In trial 3, the treatment again impacted female survival $\left(\chi^{2}=153.11, \mathrm{df}=6, p<0.0001\right.$; Figure 1), and wasps survived longest on cilantro, dill, and honey. Survival on crimson clover, mustard, and phacelia was not significantly different than the water control. The median survival for females was 5.5 days when fed with water, 4.5 days when fed with crimson clover or phacelia, 6 days when fed with mustard, 9 days when fed with cilantro, 24 days when fed with dill, and 5 days when fed with honey.

\subsection{Nutrient Levels}

In trial 4 , there was no significant difference in lipid $(\mathrm{df}=4,111 ; \mathrm{F}=1.34 ; p=0.26)$ or glycogen $(\mathrm{df}=4,111 ; \mathrm{F}=0.65 ; p=0.63$ ) levels between treatments (Figure 2). Sugar levels were equivalent for wasps fed with buckwheat and honey, and both were significantly higher than the water control $(\mathrm{df}=4,111 ; \mathrm{F}=7.65 ; p<0.001)$.

In trial 5, the lipid levels differed by treatment $(\mathrm{df}=5,167 ; \mathrm{F}=8.07 ; p<0.001$; Figure 2) and were highest for wasps fed with dill, but not significantly different than wasps fed with water, cilantro, or phacelia. Lipid levels for wasps fed with mustard were significantly lower than water controls. The lipid levels for wasps fed with crimson clover were intermediate between mustard and water. Glycogen $(\mathrm{df}=5,167 ; \mathrm{F}=4.14 ; p=0.0014)$ and sugar $(\mathrm{df}=5,167 ; \mathrm{F}=7.99 ; p<0.001)$ levels differed by treatment and were substantially higher for wasps fed with dill. Wasps fed with water, phacelia, mustard, and clover had equivalent glycogen and sugar levels. Wasps fed with cilantro were intermediate between water and dill.
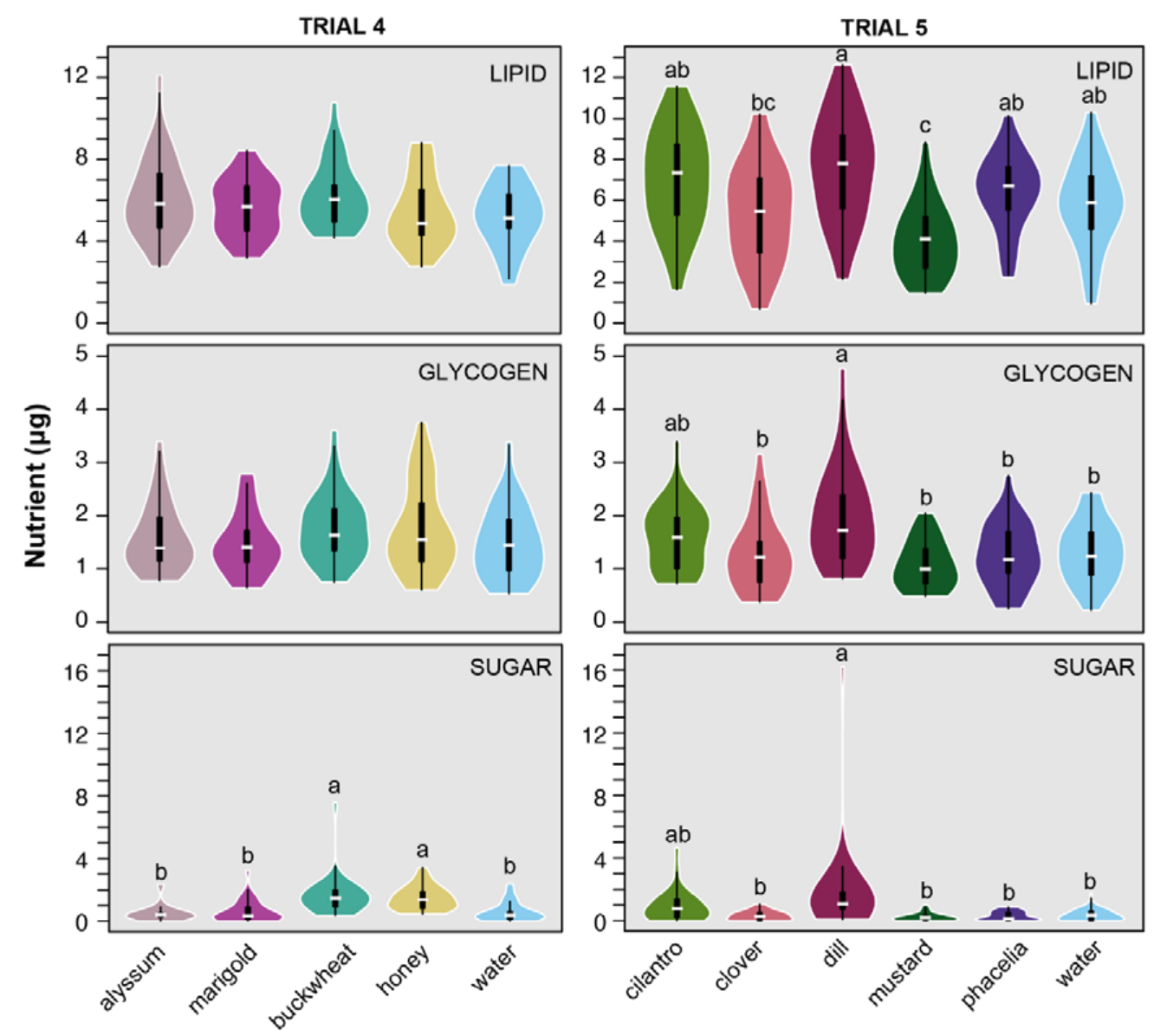

Figure 2. Kernel density plots of nutrient levels of female Trissolcus japonicus fed with flower treatments, honey, or water for $48 \mathrm{~h}$ inside vials in the lab. Internal boxplots show the median, interquartile range, maximum, and minimum. Treatments with different letters are significantly different based on Tukey post-hoc tests. 


\section{Discussion}

Of the flowers tested, buckwheat, cilantro, and dill provided the best nectar source for T. japonicus, improving the median survival by $15,3.5$, and 18.5 days compared to water, respectively. Wasps survived a maximum of 58 and 56 days on cilantro and dill, respectively. The maximal survival on buckwheat was not recorded since trial 2 ended after 30 days, but $61 \%$ of female wasps were still alive at 30 days. Feeding on buckwheat was equivalent to feeding on honey, but the results for honey were less consistent in trial 3 when wasps fed with honey did not survive as long as honey-fed wasps in the previous trials. The honey/water solution used in trial 3 may have been somehow compromised. We are confident that the other treatments in trial 3 were not compromised, since those wasps survived as expected. Wasps in trial 3 survived up to six to eight days on water as in trials 1 and 2, and some wasps with cilantro or dill survived past 30 days as wasps given buckwheat or honey in trials 1 and 2 .

Feeding on buckwheat, cilantro, and dill increased the wasps' sugar levels, which provides further confirmation of benefits of nectar feeding. Glycogen levels were increased by cilantro and dill compared to water, but not buckwheat during a two-day feeding period. This suggests that ingested cilantro and dill nectar was converted to glycogen for longer-term storage. Increased glycogen reserves in T. japonicus are likely beneficial since glycogen fuels flight and is important for overwintering in other insect species [33,34].

Nectar from buckwheat, dill, and cilantro have similarly extended longevity in other parasitoid species. When averaged over multiple studies, parasitoids fed with buckwheat showed one of the highest increases in longevity compared to other flowers, wasps fed with dill showed a moderate increase in longevity, and wasps fed with cilantro showed a small increase in longevity [15]. As in our study, wasps fed with clover (Trifolium pretense and Trifolium repens), mustard, and phacelia showed a negligible increase in longevity. Alyssum did not improve longevity for T. basalis [25]. Contrary to our study, Russell [15] reported marigold as providing a very high increase in longevity and also showed alyssum providing a moderate longevity increase in other wasp species.

Floral architecture is likely to explain the relative success of certain floral resources for T. japonicus. Corolla length and corolla opening diameter are determining factors for whether small parasitoids can access nectar $[22,35]$. We observed that $T$. japonicus were too wide and could not enter the narrow flowers of crimson clover, though they may access these nectaries in the field if bees have opened up the flowers. Flowers with shallow corollas are best for small wasps [36], which may have difficulty crawling into longer flowers. Further, across multiple studies, plants that conferred the greatest longevity benefit to parasitoids all had exposed nectaries [15]. Indeed, buckwheat, dill, and cilantro all have short corollas and exposed nectaries.

While our study has identified three promising nectar sources for T. japonicus, additional research is needed to determine if these flowers maintain their ability to improve wasp survival in the field, and whether they will increase the parasitism rate of $H$. halys. Flowers that improve parasitoid longevity do not always increase the parasitism rate [18]. For example, buckwheat floral borders extended the longevity of Diadegma insulare (Cresson) (Hymenoptera: Ichnuemonidae) females and males foraging in the field, but only marginally increased parasitism rates [16]. However, buckwheat improved the fecundity of Trissolcus basalis, and buckwheat row margins improved the parasitism of host eggs [37,38]. Floral provisioning in agroecosystems provides nutrients to many important predators and parasitoids and is generally recommended for the conservation of biological control [39] and thus merits further testing for $H$. halys management.

\section{Conclusions}

Sustainable management of $H$. halys in organic and conventional agriculture requires the development of alternative management practices. Classical biocontrol via the release of T. japonicus is promising but may be constrained by the wasp's survival and conservation in the agroecosystem. Buckwheat, cilantro, and dill are promising nectar subsidies for $T$. japonicus since they improve wasp survival and increase nutrient reserves. To determine if these flowers will help facilitate successful 
biocontrol, they need to be tested in field trials to determine if they improve the survival and longevity of T. japonicus and increase the parasitism of H. halys eggs.

Supplementary Materials: The following are available online at http://www.mdpi.com/2075-4450/11/7/413/s1, Table S1: Trissolcus japonicus floral resource data.

Author Contributions: Conceptualization, J.C.L. and V.P.S.; methodology, J.C.L., V.P.S., H.R.M., and G.G.; validation, J.C.L., V.P.S., H.R.M., and G.G.; formal analysis, J.C.L. and H.R.M.; investigation, H.R.M., V.P.S., and G.G.; resources, J.L.; writing—original draft preparation, H.R.M.; writing-review and editing, J.C.L., V.P.S., and G.G.; visualization, H.R.M.; supervision, J.C.L.; project administration, J.C.L.; funding acquisition, J.C.L. All authors have read and agreed to the published version of the manuscript.

Funding: This research was funded by the United States Department of Agriculture grant numbers 2016-51181-25409 and 2071-22000-040-00D.

Acknowledgments: We thank Caelin Alba, Leo Morag, and Emily Rutowski for their help on this project.

Conflicts of Interest: The authors declare no conflict of interest.

\section{Appendix A}

Table A1. Statistical results for male Trissolcus japonicus in trials 1-3 testing survival. Treatment differences were assessed using log-rank analysis.

\begin{tabular}{cccc}
\hline Trial & $\chi^{2}$ & df & $p<\chi^{2}$ \\
\hline 1 & 52.06 & 3 & $<0.001$ \\
2 & 28.6 & 2 & $<0.001$ \\
3 & 18.35 & 6 & 0.0054 \\
\hline
\end{tabular}

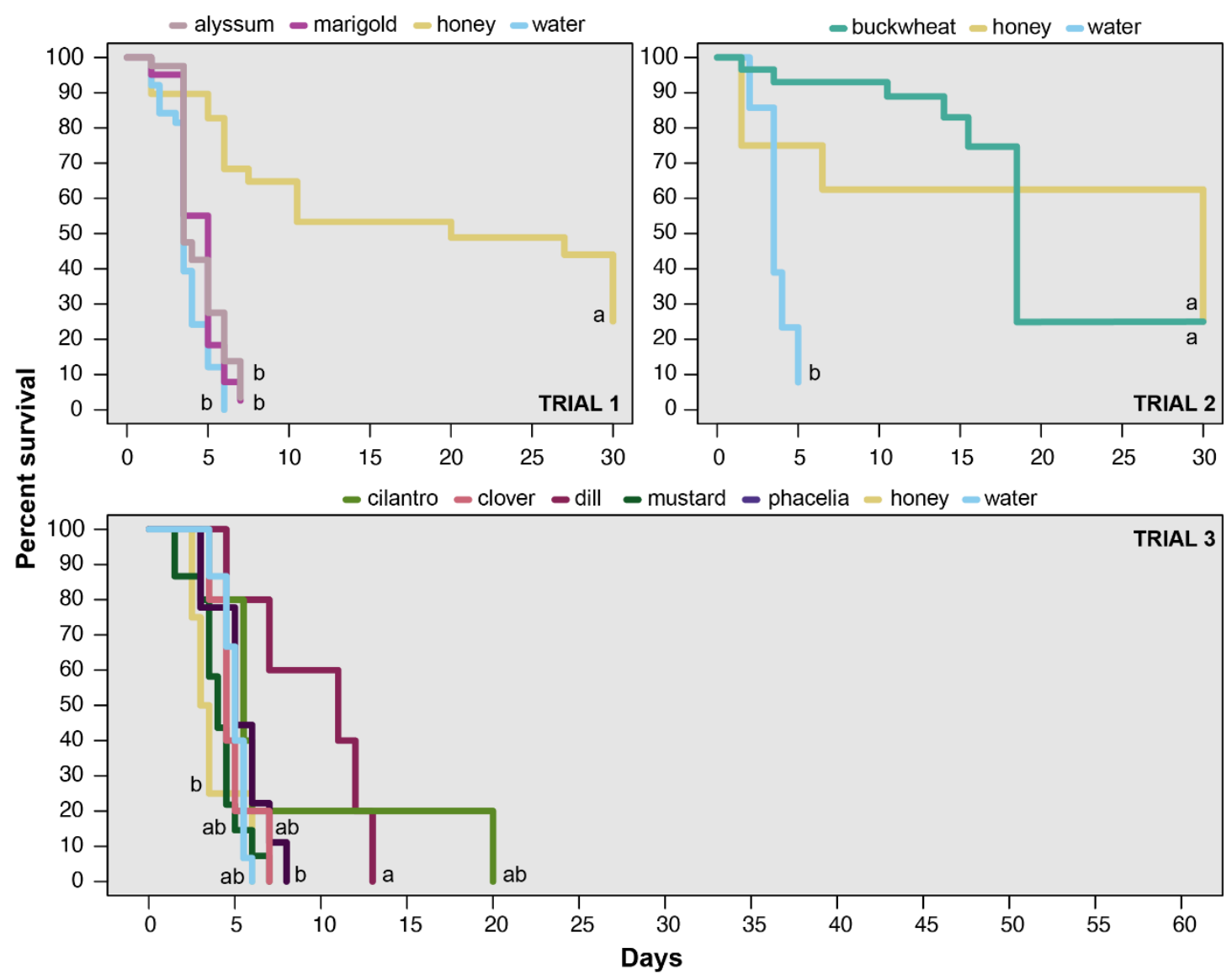

Figure A1. Survival curves of male Trissolcus japonicus fed flower treatments, honey, or water inside vials in the lab. Per results of log-rank analysis and post-hoc tests, lines with different letters are significantly different from each other. 


\section{References}

1. Hoebeke, E.R.; Carter, M.E. Halyomorpha halys (Stål) (Heteroptera: Pentatomidae): A polyphagous plant pest from Asia newly detected in North America. Proc. Entomol. Soc. Washingt. 2003, 105, 225-237.

2. Fogain, R.; Graff, S. First Records of the Invasive Pest, Halyomorpha halys (Hemiptera: Pentatomidae), in Ontario and Quebec. J. Entomol. Soc. Ontario 2011, 142, 45-48.

3. Wermelinger, B.; Wyniger, D.; Forster, B. First records of an invasive bug in Europe: Halyomorpha halys Stål (Heteroptera: Pentatomidae), a new pest on woody ornamentals and fruit trees? Bull. la Société Entomol. Suisse 2008, 81, 1-8.

4. Faúndez, E.I.; Rider, D. The brown marmorated stink bug Halyomorpha halys (Stål, 1855) (Heteroptera: Pentatomidae) in Chile. Arq. Entomolóxicos 2017, 17, 305-307. [CrossRef]

5. Leskey, T.C.; Nielsen, A.L. Impact of the Invasive Brown Marmorated Stink Bug in North America and Europe: History, Biology, Ecology, and Management. Annu. Rev. Entomol. 2018, 63, 599-618. [CrossRef]

6. Rice, K.B.; Bergh, C.J.; Bergmann, E.J.; Biddinger, D.J.; Dieckhoff, C.; Dively, G.; Fraser, H.; Gariepy, T.; Hamilton, G.; Haye, T.; et al. Biology, Ecology, and Management of Brown Marmorated Stink Bug (Hemiptera: Pentatomidae). J. Integr. Pest. Manag. 2014, 5, 1-13. [CrossRef]

7. Kuhar, T.P.; Kamminga, K. Review of the chemical control research on Halyomorpha halys in the USA. J. Pest. Sci. 2017, 90, 1021-1031. [CrossRef]

8. Lee, D.-H.; Short, B.D.; Nielsen, A.L.; Leskey, T.C. Impact of Organic Insecticides on the Survivorship and Mobility of Halyomorpha halys (Stål) (Hemiptera: Pentatomidae) in the Laboratory. Fla. Entomol. 2014, 97, 414-421. [CrossRef]

9. Yang, Z.; Yao, Y.; Qiu, L.; Li, Z.-X. A New Species of Trissolcus (Hymenoptera: Scelionidae) Parasitizing Eggs of Halyomorpha halys (Heteroptera: Pentatomidae) in China with Comments on Its Biology. Ann. Entomol. Soc. Am. 2009, 102, 39-47. [CrossRef]

10. Talamas, E.J.; Herlihy, M.V.; Dieckhoff, C.; Hoelmer, K.A.; Buffington, M.L.; Bon, M.C.; Weber, D.C. Trissolcus japonicus (Ashmead) (Hymenoptera, Scelionidae) emerges in North America. J. Hymenopt. Res. 2015, 43, 119-128. [CrossRef]

11. Milnes, J.M.; Wiman, N.G.; Talamas, E.J.; Brunner, J.F.; Hoelmer, K.A.; Buffington, M.L.; Beers, E.H. Discovery of an Exotic Egg Parasitoid of the Brown Marmorated Stink Bug, Halyomorpha halys (Stål) in the Pacific Northwest. Proc. Entomol. Soc. Washingt. 2016, 118, 466-470. [CrossRef]

12. Hedstrom, C.; Lowenstein, D.; Andrews, H.; Bai, B.; Wiman, N. Pentatomid host suitability and the discovery of introduced populations of Trissolcus japonicus in Oregon. J. Pest. Sci. 2017, 90, 1169-1179. [CrossRef]

13. Jarrett, B.J.; Pote, J.; Talamas, E.; Gut, L.; Szucs, M. The Discovery of Trissolcus japonicus (Hymenoptera: Scelionidae) in Michigan. Gt. Lakes Entomol. 2019, 52, 5.

14. Kaser, J.M.; Akotsen-Mensah, C.; Talamas, E.J.; Nielsen, A.L. First Report of Trissolcus japonicus Parasitizing Halyomorpha halys in North American Agriculture. Fla. Entomol. 2019, 101, 680. [CrossRef]

15. Russell, M. A meta-analysis of physiological and behavioral responses of parasitoid wasps to flowers of individual plant species. Biol. Control 2015, 82, 96-103. [CrossRef]

16. Lee, J.C.; Heimpel, G.E. Floral resources impact longevity and oviposition rate of a parasitoid in the field. J. Anim. Ecol. 2008, 77, 565-572. [CrossRef] [PubMed]

17. Segoli, M.; Rosenheim, J.A. Spatial and temporal variation in sugar availability for insect parasitoids in agricultural fields and consequences for reproductive success. Biol. Control 2013, 67, 163-169. [CrossRef]

18. Heimpel, G.E.; Jervis, M.A. Does floral nectar improve biological control by parasitoids. In Plant-Provided Food for Carnivorous Insects: A Protective Mutualism and Its Applications; Cambridge University Press: Cambridge, MA, USA, 2005; pp. 267-304, ISBN 9780511542220.

19. Baggen, L.R.; Gurr, G.M.; Meats, A. Flowers in tri-trophic systems: Mechanisms allowing selective exploitation by insect natural enemies for conservation biological control. Entomol. Exp. Appl. 1999, 91,155-161. [CrossRef]

20. Arévalo, H.A.; Frank, J.H. Nectar Sources for Larra bicolor (Hymenoptera: Sphecidae), a Parasitoid of Scapteriscus Mole Crickets (Orthoptera: Gryllotalpidae), in Northern Florida. Fla. Entomol. 2005, 88, $146-151$. [CrossRef]

21. Vattala, H.D.; Wratten, S.D.; Phillips, C.B.; Wäckers, F.L. The influence of flower morphology and nectar quality on the longevity of a parasitoid biological control agent. Biol. Control 2006, 39, 179-185. [CrossRef] 
22. Patt, J.M.; Hamilton, G.C.; Lashomb, J.H. Foraging success of parasitoid wasps on flowers: Interplay of insect morphology, floral architecture and searching behavior. Entomol. Exp. Appl. 1997, 83, 21-30. [CrossRef]

23. Koptur, S. Nectar as fuel for plant protectors. In Plant-Provided Food for Carnivorous Insects: A Protective Mutualism and Its Applications; Cambridge University Press: Cambridge, MA, USA, 2005; pp. 75-108, ISBN 9780511542220.

24. Kaser, J.; Dieckhoff, C.; Hoelmer, K. Reproduction and sperm limitation of the egg parasitoid Trissolcus japonicus. Biol. Control. In preparation.

25. Rahat, S.; Gurr, G.M.; Wratten, S.D.; Mo, J.; Neeson, R. Effect of plant nectars on adult longevity of the stinkbug parasitoid, Trissolcus basalis. Int. J. Pest. Manag. 2005, 51, 321-324. [CrossRef]

26. Steiner, G. Nematodes parasitic on and associated with roots of marigolds (Tagetes hybrids). Proc. Biol. Soc. Washingt. 1941, 54, 31-34.

27. Souza, I.L.; Marucci, R.C.; Silveira, L.C.P.; de Paulo, N.C.P.; Lee, J.C. Effects of marigold on the behavior, survival and nutrient reserves of Aphidius platensis. BioControl 2018,63, 543-553. [CrossRef]

28. Lee, J.C. What we can learn from the energetic levels of insects: A guide and review. Ann. Entomol. Soc. Am. 2019, 112, 220-226. [CrossRef]

29. McIntosh, H.; Lowenstein, D.M.; Wiman, N.G.; Wong, J.S.; Lee, J.C. Parasitism of frozen Halyomorpha halys eggs by Trissolcus japonicus: Applications for rearing and experimentation. Biocontrol Sci. Technol. 2019, 29, 478-493. [CrossRef]

30. Van Handel, E. Rapid determination of total lipids in mosquitoes. J. Am. Mosq. Control. Assoc. 1985, 1, 302-304.

31. Van Handel, E. Rapid determination of glycogen and sugars in mosquitoes. J. Am. Mosq. Control. Assoc. 1985, 1, 299-301.

32. SAS Version 9.3; SAS Institute Inc.: Cary, NC, USA, 2016.

33. Hahn, D.A.; Denlinger, D.L. Meeting the energetic demands of insect diapause: Nutrient storage and utilization. J. Insect Physiol. 2007, 53, 760-773. [CrossRef]

34. Beenakkers, A.M.T.; Van der Horst, D.J.; Van Marrewijk, W.J.A. Insect flight muscle metabolism. Insect Biochem. 1984, 14, 243-260. [CrossRef]

35. Idris, A.B.; Grafius, E. Wildflowers as nectar sources for Diadegma insulare (Hymenoptera: Ichneumonidae), a parasitoid of diamondback moth (Lepidoptera: Yponomeutidae). Environ. Entomol. 1995, 24, 1726-1735. [CrossRef]

36. Orr, D.B.; Pleasants, J.M. The potential of native prairie plant species to enhance the effectiveness of the Ostrinia nubilalis parasitoid Macrocentrus grandii. J. Kans. Entomol. Soc. 1996, 69, 133-143. [CrossRef]

37. Foti, M.C.; Peri, E.; Wajnberg, E.; Colazza, S.; Rostás, M. Contrasting olfactory responses of two egg parasitoids to buckwheat floral scent are reflected in field parasitism rates. J. Pest. Sci. 2019, 92, 747-756. [CrossRef]

38. Foti, M.C.; Rostás, M.; Peri, E.; Park, K.C.; Slimani, T.; Wratten, S.D.; Colazza, S. Chemical ecology meets conservation biological control: Identifying plant volatiles as predictors of floral resource suitability for an egg parasitoid of stink bugs. J. Pest. Sci. 2017, 90, 299-310. [CrossRef]

39. Landis, D.A.; Wratten, S.D.; Gurr, G.M. Habitat Management to Conserve Natural Enemies of Arthropod Pests in Agriculture. Annu. Rev. Entomol. 2000, 45, 175-201. [CrossRef]

(C) 2020 by the authors. Licensee MDPI, Basel, Switzerland. This article is an open access article distributed under the terms and conditions of the Creative Commons Attribution (CC BY) license (http://creativecommons.org/licenses/by/4.0/). 